\title{
МОРФОБІОМЕХАНІЧНІ ОСОБЛИВОСТІ СТУДЕНТОК З РІЗНИМ ТИПОМ ТІЛОБУДОВИ
}

\begin{abstract}
Мета. Визначити морфобіомеханічні особливості студенток 17-18 років різних типів тілобудови. Для розв'язання поставлених завдань використовувався комплекс наступних методів: теоретичні, емпіричні, статистичні. Методи. У дослідженні прийняла участь 121 студентка. Соматотип визначали за індексом Пінє. В прочесі антропометричного обстеження визначали обводи різних біоланок тіла, вагу та довжину тіла. Для вимірювання кутів, щуо характеризують біогеометричний про-

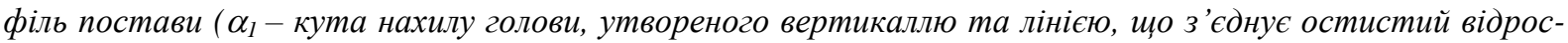

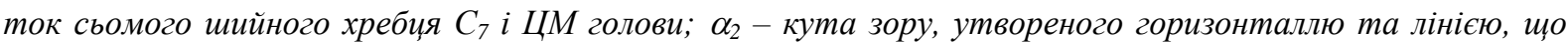
з'єднує найбільи виступаючу частину лобної кістки та підборідний виступ; $\alpha_{3}$ - кута нахилу тулуба, утвореного вертикаллю та лінією, щуо з'єднує остистий відросток сьомого иийного хребия $\left(C_{7}\right)$ застосовували гоніометрію, а фотограми обробляли із використанням компютерної програми “Тогsо”. Результати. Встановлено що студентки, які прийняли участь у дослідженні мають наступний типи тілобудови: 64 - мезоморфний, 35 - ектоморфний та 22 особи - ендоморфний соматитип. Студентки ектоморфного соматотипу мають найбільші показники довжини, а представниці ендоморфного типу тіло будови ваги тіла. Щодо величини обводів різних біоланок тіла, то вони у студенток мезоморфного соматотипу, в порівнянні з особами інших типів тіло будови, є найбільшими. У результаті проведеного дослідження вивчено особливості просторової організачії тіла у студенток 17-18 років з різним соматотипом, зокрема, визначено кутові характеристики біогеометричного профілю постави. Проведені дослідження дозволили створити антропометричні моделі студенток 17-18 років. Висновок. Тіло будова має виражені статеві, вікові та індивідуальні особливості, а тому із системних позицій може розглядатись як взаємозалежна та взаємозумовлена сукупність морфо-функціональних компонентів тіла людини.
\end{abstract}

Ключові слова: студентки, морфобіомеханічні особливості, тілобудова, корекиія, кутові характеристики.

Aim. To determine the morphobiomechanical peculiarities of 17-18 year-old female students of different body types. To solve the tasks there was used a set of the following methods: theoretical, empirical, statistical. Methods. 121 female students participated in the study. The somatotype was determined according to Pinye index. In the process of anthropometric examination, different body biolinks contours, body weight and length were determined. To measure the angles characterizing the biogeometric posture profile ( $a^{l}$ is the head inclination angle formed by vertical and line connecting the spinous process of the seventh cervical vertebra $C^{7}$ and CM of the head; $a^{2}$ is the angle formed by horizontal and line connecting the most prominent point of frontal bone and chin; $a^{3}$ is the angle of torso inclination formed by the vertical and the line connecting the spinous process of the seventh cervical vertebra $\left(C^{7}\right)$ there was used gonometry, and photogrammes were processed using "Torso" program. Results. It was found that of all female students who participated in the study have 64 had mesomorphic body type, 35 had ectomorphic and 22 had endomorphic somatotype. Female Students of ectomorphic somatotype have the highest length indicators, and endomorphic type students - body weight indicators. According to size of body biolinks contours, they are the largest in mesomorphic somatotype students, compared to other body structure types representatives. As a result of conducted research the spatial body organization peculiarities in 17-18 year-old female with different somatotype were studied, in particular, the angular characteristics of the biogeometric posture profile were determined. The conducted researches allowed to create anthropometric models of 17-18 year-old female students. Conclusion. The body structure has pronounced sexual, age and individual characteristics, and therefore can be considered as an interdependent and interrelated set of morpho-functional human body components.

Keywords: female students, morphobiomechanical peculiarities, physique, correction, angular characteristics.

Постановка проблеми й аналіз результатів останніх досліджень. Біологічна система організму людини, унаслідок взаємодії з навколишнім середовищем, зазнає постійних змін у часі та просторі, а відтак визначається величинами таких змінних параметрів $[11,12,13]$. Онтогенез людського тіла передбачав, зокрема, формування останнього шляхом розташування всієї його маси у поздовжньому напрямі й паралельно до 
вектора гравітації, а також концентрування основних мас біоланок на відносно невеликих відстанях від неї $[8,16,17]$. Такий розподіл мас зумовив симетричність біомеханічної конструкції рухової системи людини та забезпечив їй можливість більш ефективного керування гравітаційними взаємодіями під час переміщення свого тіла $[11,15]$.

За даними наукової спільноти $[1,2,14]$ тілобудова $€$ формою прояву природного біологічного розмаїття, яке $є$ дискретним, що визначає природний склад типології варіантів конституції. Варто відмітити, що тілобудова відображає основні особливості динаміки онтогенезу, метаболізму, реактивності організму $[7,9,11]$. Згідно наявним уявленням $[18,19]$ зазначені властивості формують індивідуальні особливості структури, а отже, і функції організму, визначають його реакцію на фактори зовнішнього середовища, які постійно змінюються.

Трансформація сучасних наукових ідей в стратегію оздоровлення студентської молоді, вимагають розробки і впровадження ефективних новаторських технологій [5, 6]. В даний час найбільш популярними й ефективними засобами корекції тілобудови $€$ різні системи оздоровчого фітнесу. В умовах сьогодення відбувається зміна парадигми фізичного виховання, що вимагає визначення інтересів і потреб у сфері тілесного й духовного вдосконалення студентів. Багато питань, щодо корекції тілобудови студенток з урахуванням особливостей геометрії мас їхнього тіла, усе ще оптимально не розв'язано.

Мета дослідження - визначити морфо-біомеханічні особливості студенток 17-18 років різних типів тіло будови.

Методи й організація дослідження. Для розв'язання поставлених завдань використовуватимуться комплекс наступних методів:

- теоретичні - проводилися з метою вивчення й обгрунтування вихідних положень дослідження, визначення його проблемного поля, узагальнення досвіду науковців, які займаються вивченням проблеми корекції тіло будови студенток; емпіричні: антропометричне обстеження студенток із застосуванням стандартного інструментарію та на основі загальноприйнятої уніфікованої методики; визначення соматотипу за допомогою індексу Піньє. Для реєстрації кількісних характеристик, які відображають стан постави студентів, послуговувалися цифровою відеокамерою, під’єднаною до персонального комп'ютера із завантаженою програмою “Тorso". Відеознімання відбувалося із дотриманням основних біомеханічних вимог, серед яких: позначення центрів суглобів та анатомічних міток стопи контрастними маркерами; розміщення у площині об'єкта знімання масштабної лінійки (знімання стопи вимагало поділу останньої на двох сантиметрові кольорові ділянки, а відеофіксація ходьби та постави - постановки метрової лінійки); закріплення камери на штативі нерухомо та на відстані 3-х метрів від об'єкта знімання (для статичних поз). Фотограми біогеометричного профілю постави обробляли із використанням програми “Тorso" для визначення трьох кутових характеристик біогеометричних показників постави: $\alpha_{1}$ - кута нахилу голови, утвореного вертикаллю та лінією, що з'єднує остистий відросток сьомого шийного хребця $\mathrm{C}_{7}$ і ЦМ голови; $\alpha_{2}$ - кута зору, утвореного горизонталлю та лінією, що з'єднує найбільш виступаючу частину лобної кістки та підборідний виступ; $\alpha_{3}-$ кута нахилу тулуба, утвореного вертикаллю та лінією, що з'єднує остистий відросток сьомого шийного хребця $\left(\mathrm{C}_{7}\right)$ - найбільш виступаюча частина хребта на стику шийного та грудного відділів - та остистий відросток п'ятого поперекового хребця $\left(\mathrm{L}_{5}\right)$ - найбільш лордично заглиблена мітка поперекового лордозу (центр соматичної системи координат) $[3,4,8]$. Кількісні показники обробляли за допомогою загальноприйнятих методів математичної статистики 3 обчисленням середніх величин $(\bar{x})$; середніх квадратичних відхилень (S); помилки репрезентативності (m). У ході визначення статистичної достовірності відмін- 
ностей між вибірковими показниками, розподіл яких не відповідав нормальному закону, оперували непараметричними критеріями: для незалежних вибірок - U-критерієм Манна-Вїтні, для залежних - критерієм Вілкоксона. Усі розрахунки виконували за допомогою комп'ютерних програм STATISTICA 7, Statistica 6.0, розроблених фірмами Microsoft, Statsoft.

У констатувальному експерименті прийняла участь 121 студентка 17-18 років. Дослідження проведено на базі Київського національного економічного університету.

Результати досліджень. За допомогою індексу Піньє встановлено, що з обстежених 121 студентки 64 мали мезоморфний, 35 - ектоморфний та 22 особи - ендоморфний соматитип.

Водночас виявлено, що студентки ектоморфного соматотипу характеризуються найбільшими показниками довжини тіла. Натомість у представниць ендоморфного соматотипу довжина тіла виявилася найменшою (табл. 1).

Таблииа 1

Характеристика фізичного розвитку студенток $17-18$ років $(\mathrm{n}=121)$

\begin{tabular}{|c|c|c|c|c|c|c|}
\hline \multirow{3}{*}{$\begin{array}{c}\text { Соматометрічні } \\
\text { показники }\end{array}$} & \multicolumn{6}{|c|}{ Тип тілобудови } \\
\hline & \multicolumn{2}{|c|}{$\begin{array}{c}\text { Ектоморфний } \\
n=35\end{array}$} & \multicolumn{2}{|c|}{$\begin{array}{c}\text { Ендоморфний } \\
\text { n=22 }\end{array}$} & \multicolumn{2}{|c|}{$\begin{array}{c}\text { Мезоморфний } \\
\mathrm{n}=64\end{array}$} \\
\hline & $x$ & S & $x$ & S & $x$ & $S$ \\
\hline Вага тіла, кг & $54,5 * * * \ldots$ & 3,81 & $63,4 * * *$ & 4,90 & 58,1 & 4,52 \\
\hline Довжина тіла, см & $168,7 * \bullet$ & 4,12 & 164,7 & 4,71 & 166,7 & 4,61 \\
\hline Обвід грудної клітки, см & $77,5 * * * . .$. & 5,80 & $91,2 * * *$ & 6,02 & 85,3 & 5,50 \\
\hline Обвід плеча, см & $23,3 * * * \ldots$ & 3,71 & 28,0 & 3,80 & 26,2 & 3,81 \\
\hline Обвід живота, см & $64,9 * * * .$. & 4,44 & $75,4 * * *$ & 4,83 & 68,1 & 5,51 \\
\hline Обвід таза, см & $88,8 * * * . . \bullet$ & 5,50 & $97,8^{*}$ & 6,53 & 94,5 & 4,22 \\
\hline Обвід стегна, см & $52,1 * * \bullet \bullet \bullet$ & 4,94 & $58,3^{* *}$ & 4,25 & 55,0 & 3,80 \\
\hline Обвід гомілки, см & $33,3 * \bullet$ & 2,81 & $35,9 *$ & 2,15 & 34,6 & 1,84 \\
\hline
\end{tabular}

Примітки: *- відмінності статистично значущі порівняно з показниками мезоморфів $(*-\mathrm{p}<0,05 ; * *-\mathrm{p}<0,01 ; * * *-\mathrm{p}<0,001) ;-$ - відмінності статистично значущі між показниками у групах ендо- та ектоморфів $(\bullet-\mathrm{p}<0,01 ; \cdots-\mathrm{p}<0,001)$.

Як видно з табл. 1, студентки ендоморфного соматотипу мають найбільшу вагу тіла, а найменшу представниці ектоморфного соматотипу (див. табл. 1). При аналізі величини обводів різних біоланок тіла встановлено, що вони у студенток мезоморфного соматотипу, в порівнянні зі студентками інших типів тіло будови, є найбільшими (див. табл. 1).

На підставі отриманих даних нами розроблені антропометричні моделі студенток 3 різним типом тіло будови (рис. 1).

Особливості просторової організації тіла у студенток 17-18 років 3 різним соматотипом, зокрема, кутові характеристики біогеометричного профілю постави наведені в табл. 2. Необхідно відзначити, що згідно з отриманими даними всі три досліджувані кутові показники відповідали нормальним величинам [5,6]. Аналізуючи дані гоніометрії встановлено, що у студенток в 17-18 років з різним типом тіло будови найбільш виражені зміни відбуваються у таких показниках, як кут, утворений вертикаллю і лінією, що з'єднує остисті відростки хребців $\mathrm{C}_{\mathrm{VII}}$ i $\mathrm{L}_{\mathrm{V}}\left(\alpha_{3}\right)$. При цьому у осіб ендоморфного соматотипу кут $\left(\alpha_{3}\right)$ має найменшу величину (див. табл. 2). 


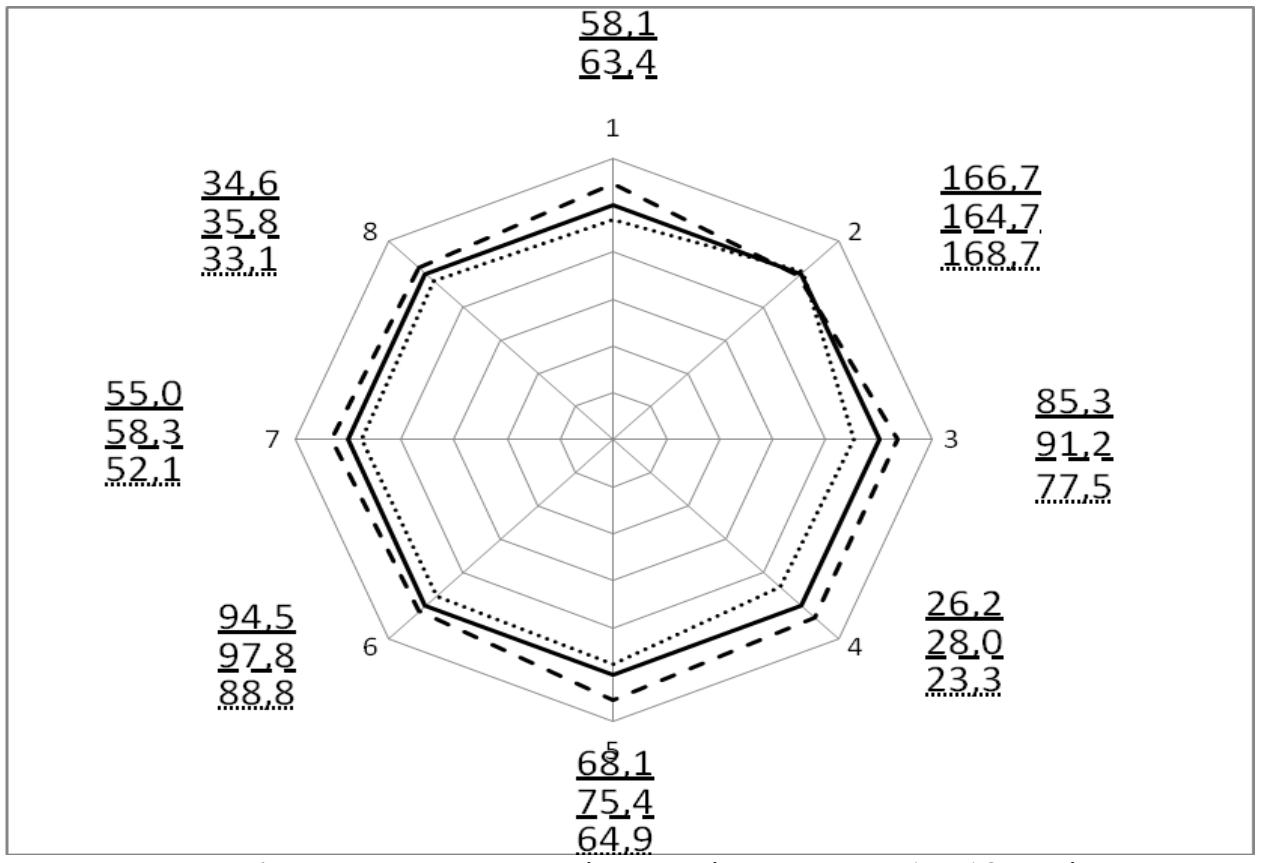

Pис. 1. Антропометричні моделі студенток 17-18 років

1 - вага тіла, кг; 2 - довжина тіла, см; 3 - обвід грудної клітки, см; 4 - обвід плеча, см; 5 - обвід живота, см; 6 - обвід тазу, см; 7 - обвід стегна, см; 8 - обвід гомілки, см;

- - соматометричні показники мезоморфів;

- - - - - - соматометричні показники ендоморфів;

- соматометричні показники ектоморфів

Таблица 2

Гоніометричні характеристики сагітального профілю постави студенток 3 різним типом тілобудови $(\mathbf{n}=121)$

\begin{tabular}{|c|c|c|c|c|c|c|c|}
\hline \multirow[t]{3}{*}{ Гоніометричні показники } & \multirow{3}{*}{ 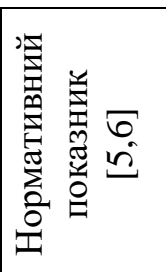 } & \multicolumn{6}{|c|}{ Тип тілобудови } \\
\hline & & \multicolumn{2}{|c|}{$\begin{array}{c}\text { Ектоморфний } \\
\mathrm{n}=35\end{array}$} & \multicolumn{2}{|c|}{$\begin{array}{c}\text { Ендоморфний } \\
\mathrm{n}=22\end{array}$} & \multicolumn{2}{|c|}{$\begin{array}{c}\text { Мезоморфний } \\
n=64\end{array}$} \\
\hline & & $\bar{x}$ & S & $\bar{x}$ & $\mathrm{~S}$ & $\bar{x}$ & $S$ \\
\hline $\begin{array}{l}\text { Кут, утворений вертикаллю і лінією, } \\
\text { що з’єднує остистий відросток хреб- } \\
\text { ця С } \mathrm{C}_{\mathrm{VII}} \text { і ЦМ голови }\left(\alpha_{1}\right)\end{array}$ & $\begin{array}{c}30,93^{\circ} \\
(\mathrm{S}=0,64)\end{array}$ & 30,55 & 1,08 & 30,76 & 1,02 & 30,91 & 0,96 \\
\hline $\begin{array}{l}\text { Кут, утворений горизонталлю і лі- } \\
\text { нією, що з’єднує найбільш висту- } \\
\text { паючу точку лобової кістки і виступ } \\
\text { підборіддя }\left(\alpha_{2}\right)\end{array}$ & $\begin{array}{c}89,61^{\circ} \\
(\mathrm{S}=0,61)\end{array}$ & 89,44 & 0,57 & 89,47 & 0,55 & 89,59 & 0,83 \\
\hline $\begin{array}{l}\text { Кут, утворений вертикаллю і лінією, } \\
\text { що з’єднує остисті відростки хребців } \\
\mathrm{C}_{\mathrm{VII}} \text { i } \mathrm{L}_{\mathrm{V}}\left(\alpha_{3}\right)\end{array}$ & $\begin{array}{c}2,05^{\circ} \\
(\mathrm{S}=0,54)\end{array}$ & 2,96 & 0,51 & 2,82 & 0,67 & 2,84 & 0,64 \\
\hline
\end{tabular}

Дискусія. Гоніометричні показники є важливими для визначення спрямованості педагогічних впливів $[3,5,8]$ при організації фізичної підготовки студенток (так, наприклад, зменшення кута, утвореного вертикаллю і лінією, що з'єднує остистий відросток хребця $\mathrm{C}_{\mathrm{VII}}$ і центр масс (ЦМ) голови $\left(\alpha_{1}\right)$ свідчить про перевантаження скелетних м'язів задньої області шийного відділу хребетного стовпа і на стику його шийного i грудного відділів; збільшення кута, утвореного вертикаллю і лінією, що з’єднує остисті 
відростки хребців $\mathrm{CV}_{\text {II }}$ i $\mathrm{L}_{\mathrm{V}}$ при різних порушеннях просторової організації тіла свідчить про значні зусилля, які додаються до важеля в цій області для утримання вертикального положення хребетного стовпа) [1]. Найчастіше причиною збільшення кута нахилу тулуба є слабка мускулатура живота) [19].

\section{Висновки.}

1. Тіло будова має виражені статеві, вікові та індивідуальні особливості, а тому із системних позицій може розглядатись як взаємозалежна та взаємозумовлена сукупність морфо-функціональних компонентів тіла людини. Встановлено, що студентки ектоморфного соматотипу мають найбільшу довжину, а представниці ендоморфної тілобудови, вагу тіла.

2. Щодо величини обводів різних біоланок тіла, то вони у студенток мезоморфного соматотипу, в порівнянні зі студентками інших типів тілобудови, $є$ найбільшими.

3. Результати дослідження просторової організації тіла студенток 17-18 років 3 різним соматотипом засвідчили, що всі три кутові показник (кут, утворений вертикаллю і лінією, що з'єднує остистий відросток хребця $\mathrm{C}_{\mathrm{VII}}$ і центр масс голови $\left(\alpha_{1}\right)$; кут, утворений вертикаллю і лінією, що з'єднує остисті відростки хребців $\mathrm{CV}_{\mathrm{II}}$ i $\mathrm{L}_{\mathrm{V}}$; кута нахилу тулуба) відповідають нормальним величинам.

1. Випасняк I, Шанковський А. Особливості гоніометрії тіла студентів із різними типами постави = Features of goniometry of students with different types of posture. Journal of Education, Health and Sport [Інтернет]. 2017; 7 (5): 1026-1040. Доступно: http://ojs.ukw.edu.pl/index.php/johs/article/view/5123.

2. Випасняк ІП, Лещак ОМ, Шанковський АЗ. Особливості компонентів фізичного розвитку студентів в процесі фізичного виховання в залежності від типу тілобудови. Науковий часопис НПУ імені М.П. Драгоманова. Серія: Науково-педагогічні проблеми фізичної культури (фізична культура і спорт). 2018; 3 (97): 19-23.

3. Кашуба ВА. Биодинамика осанки школьников в процессе физического воспитания: дис. на соискание ученой степени д-ра наук по физ. воспитанию и спорту: спец. 24.00.02. Киев, 2003. 40 с.

4. Кашуба ВА, Адель Бен Жедду. Профилактика и коррекция нарушений пространственной организации тела человека в процессе физического воспитания. К.: Знания Украины, 2005. 158 с.

5. Кашуба В О, Рудницький ОВ, Гонадзе ЮК. Інноваційні підходи в фізичному вихованні студентської молоді з різними типами тілобудови. Актуальні проблеми фізичної культури, спорту, фізичної терапії та ерготерапії: біомеханічні, психофізіологічні та метрологічні аспекти: Матеріали I Bceукраїнської електронної науковопрактичної конференції з міжнародною участю (Київ, 17 травня 2018 р.). $185-189$ (a).

6. Кашуба В, Рудницкий А. Современные технологии коррекции телосложения занимающихся средствами оздоровительного фитнеса. Revistă teoretico-tiinţifică “Stiinţa culturii fizice". 2016; 25(1): 96-102.

7. Кашуба В, Лопацький C, Хабінець Т. Просторова організація тіла людини в процесі моніторингових досліджень. Молодіжний науковий вісник Східноєвропейського національного університету імені Лесі Українки. Фізичне виховання і спорт : журнал / уклад. А. В. Цьось, А. І. Альошина. Луцьк: Східноєвроп. нац. ун-т ім. Лесі Українки, 2017; 25: 9-15.

8. Кашуба В. Попадюха Ю. Біомеханіка просторової організації тіла людини: сучасні методи та засоби діагностики і відновлення порушень: монографія. К. Центр учбової літератури. 2018. 768 с.

9. Кашуба В, Лопацький С. Теоретико-практичні аспекти моніторингу просторової організації тіла людини: монографія. Івано-Франківськ: Видавець Кушнир Г.М., 2018. 232 с.

10. Кашуба В, Гончарова Н, Ткачова А, Прилуцька Т. Особливості тілобудови жінок першого періоду зрілого віку, які займаються аквафітнесом. Спортивний вісник Придніпров'я. 2019;1:97-104.

11. Лапутин АН, Кашуба ВА. Формирование массы и динамика гравитационных взаимодействий тела человека в онтогенезе. Київ: Знання, 1999. 202 с.

12. Лапутін АМ, Кашуба ВО. Динамічна анатомія: Навчальна програма для вузів фізичного виховання та спорту. Київ: Науковий світ, 2000. 12 с.

13. Лапутін АМ, Кашуба ВО. Кінетика тіла людини: навчальна програма для ВНЗ фізичного виховання та спорту. Київ: Науковий світ, 2003. 13 с.

14. Мицкан БМ, Випасняк ІП, Шанковський АЗ. Факторна структура показників фізичного розвитку, фізичної підготовленості, тіло будови та стану біогеометричного профілю постави студентів в 
процесі фізичного виховання. Науковий часопис НПУ імені М.П. Драгоманова. Серія: Науковопедагогічні проблеми фізичної культури (фізична культура і спорт). 2018; 4(98): 106-110.

15. Andrieieva O, Hakman A, Kashuba V, Vasylenko M, Patsaliuk K, Koshura A, Istyniuk I. Effects of physical activity on aging processes in elderly persons Journal of Physical Education and Sport ${ }^{\circledR}$ (JPES), 2019; 19: 1308-1314.

16. Kashuba V, Lopatskyi S, Prylutska T. Contemporary points on monitoring the spatial organization of the human body in the process of physical education Journal of Education, Health and Sport, 2017; 7(6): 1243-1254.

17. Kashuba Vitaliy, Asaulyuk Inna, Dyachenko Anna. Characteristics of the biogeometric profile of students' posture in the process of vocational and physical training. Journal of Education, Health and Sport. 2017; 7(6): 1255-1264. DOI http://dx.doi.org/10.5281/zenodo.2548845.

18. Kashuba V, Kolos M, Rudnytskyi O, Yaremenko V, Shandrygos V, Dudko M, Andrieieva O. Modern approaches to improving body constitution of female students within physical education classes. Journal of Physical Education and Sport. 2017;17 (4): 2472-2476. doi: 10.7752/jpes.2017.04277.

19. Tkachova A, Dutchak M, Kashuba V, Goncharova N, Lytvynenko Y, Vako I, Kolos S, Lopatskyi S. Practical implementation of differentiated approach to developing water aerobics classes for early adulthood women with different types of body build. Journal of Physical Education and Sport (JPES). 2020; 20(1): 456-60.

\section{References}

1. Vipasnyak I, Shankovskiy A. Features of goniometry of students with different types of posture. Journal of Education, Health and Sport. 2017; 7(5): 1026-1040. http://ojs.ukw.edu.pl/index.php/johs/article/ view/5123.

2. Vypasnyak IP, Leshchak OM, Shankovs'kyy AZ. Features of components of physical development of students in the process of physical education depending on the type of physique. Scientific journal of NPU National Pedagogical Dragomanov University. Series: Scientific and pedagogical problems of physical culture (physical culture and sports). 2018; 3 (97): 19-23.

3. Kashuba VA. Biodynamics of posture of schoolchildren in the process of physical education: dis. for the degree of Doctor of Science in Phys. education and sports: specials. 24.00.02. Kiev, 2003. 40 p.

4. Kashuba VA, Adele Ben Jeddu. Prevention and correction of violations of the spatial organization of the human body in the process of physical education. K.: Knowledge of Ukraine, 2005. 158 p.

5. Kashuba VO, Rudnyts'kyy OV, Honadze YUK. Innovative approaches in physical education of student youth with different body types. Current issues of physical culture, sports, physical therapy and occupational therapy: biomechanical, psychophysiological and metrological aspects: Proceedings of the I All-Ukrainian electronic scientific-practical conference with international participation (Kyiv, May 17, 2018). 185189 (a)

6. Kashuba V, Rudnitskiy A. Modern technologies for correcting the physique of those involved in healthimproving fitness. Revistă teoretico-tiinţifică "Stiinţa culturii fizice". 2016; 25(1): 96-102.

7. Kashuba V, Lopats'kyy S, Khabinets' T. Spatial organization of the human body in the process of monitoring studies. Youth Scientific Bulletin of the Lesia Ukrainka East European National University. Physical education and sports: magazine / style. AV. Ts'os', AI. Al'oshyna. Lutsk: Eastern Europe. nat. Univ. Lesya Ukrainka, 2017; 25: 9-15.

8. Kashuba V. Popadyukha Y. Biomechanics of spatial organization of the human body: modern methods and tools for diagnosis and recovery of disorders: a monograph. K. Center for Educational Literature. 2018. 768 p.

9. Kashuba V, Lopats'kyy S. Theoretical and practical aspects of monitoring the spatial organization of the human body: a monograph. Ivano-Frankivsk: Publisher Kushnir GM, 2018. 232 p.

10. Kashuba V, Honcharova N, Tkachova A, Pryluts'ka T. Peculiarities of the physique of women of the first period of adulthood who are engaged in aqua fitness. Sportyvnyy visnyk Prydniprov"ya. 2019; 1: 97-104.

11. Laputin AN, Kashuba VA. Formation of mass and dynamics of gravitational interactions of the human body in ontogenesis. Kiev: Znannya, 1999.202 p.

12. Laputin AM, Kashuba VO. Dynamic Anatomy: Curriculum for Physical Education and Sports. Kyiv: Scientific World, 2000. 12 p.

13. Laputin AM, Kashuba VO. Kinetics of the human body: a curriculum for universities of physical education and sports. Kyiv: Scientific World, 2003. 13 p.

14. Mytskan BM, Vypasnyak IP, Shankovs'kyy AZ. Factor structure of indicators of physical development, physical fitness, body structure and state of biogeometric profile of students' posture in the process of physical education. Scientific journal National Pedagogical Dragomanov University . Series: Scientific and pedagogical problems of physical culture (physical culture and sports). 2018; 4 (98): 106-110. 
15. Andrieieva O, Hakman A, Kashuba V, Vasylenko M, Patsaliuk K, Koshura A, Istyniuk I. Effects of physical activity on aging processes in elderly persons Journal of Physical Education and Sport ${ }^{\circledR}$ (JPES), 2019; 19: 1308-1314.

16. Kashuba V, Lopatskyi S, Prylutska T. Contemporary points on monitoring the spatial organization of the human body in the process of physical education Journal of Education, Health and Sport, 2017; 7(6): 1243-1254.

17. Kashuba Vitaliy, Asaulyuk Inna, Dyachenko Anna. Characteristics of the biogeometric profile of students' posture in the process of vocational and physical training. Journal of Education, Health and Sport. 2017; 7(6): 1255-1264. DOI http://dx.doi.org/10.5281/zenodo.2548845.

18. Kashuba V, Kolos M, Rudnytskyi O, Yaremenko V, Shandrygos V, Dudko M, Andrieieva O. Modern approaches to improving body constitution of female students within physical education classes. Journal of Physical Education and Sport. 2017; 17 (4): 2472-2476. doi: 10.7752/jpes.2017.04277.

19. Tkachova A, Dutchak M, Kashuba V, Goncharova N, Lytvynenko Y, Vako I, Kolos S, Lopatskyi S. Practical implementation of differentiated approach to developing water aerobics classes for early adulthood women with different types of body build. Journal of Physical Education and Sport (JPES). 2020; 20(1): 456-60.

Цитування на цю статтю:

Альошина AI, Матійчук ВI, Остап’як ЗМ. Морфобіомеханічні особливості студенток 3 різним типом тілобудови . Вісник Прикарпатського університету. Серія: Фізична культура. 2020 Листоп 03; 35: 3-9

\begin{tabular}{|c|c|}
\hline Відомості про автора: & Information about the author: \\
\hline $\begin{array}{l}\text { Альошина Алла Іванівна - доктор наук з фізично- } \\
\text { го виховання і спорту, професор, завідувач кафед- } \\
\text { ри спортивно-масової та туристичної роботи, Схід- } \\
\text { ноєвропейський національний університет імені } \\
\text { Лесі Українки (Луцьк, Україна) }\end{array}$ & $\begin{array}{l}\text { Alyoshina Alla Ivanivna - Doctor of Physical Edu- } \\
\text { cation and Sports, Professor, Head of the Department } \\
\text { of Sports and Mass and Tourist Work, Lesya Ukrainka } \\
\text { Eastern European National University (Lutsk, } \\
\text { Ukraine) }\end{array}$ \\
\hline \multicolumn{2}{|l|}{$\begin{array}{l}\text { e-mail: aleshina1012@gmail.com } \\
\text { https://orcid.org/ 0000-0001-6517-1984 }\end{array}$} \\
\hline $\begin{array}{l}\text { Матійчук Вікторія Ігорівна - аспірант, Східно- } \\
\text { європейський національний університет імені Лесі } \\
\text { Українки (Луцьк, Україна) }\end{array}$ & $\begin{array}{l}\text { Matiychuk Victoria Ihorivna - graduate student, } \\
\text { Lesya Ukrainka Eastern European National University } \\
\text { (Lutsk, Ukraine) }\end{array}$ \\
\hline \multicolumn{2}{|l|}{ https://orcid.org/0000-0001-8484-892X } \\
\hline $\begin{array}{l}\text { Остап'як Зіновій Миколайович - доктор медич- } \\
\text { них наук, професор, ДВНЗ “Прикарпатський націо- } \\
\text { нальний університет імені Василя Стефаника” } \\
\text { (Івано-Франківськ, Україна) }\end{array}$ & $\begin{array}{l}\text { Ostapiak Zinovii Mykolaiovych-Doctor of Medical } \\
\text { Science, Professor, Vasyl Stefanyk Precarpathian } \\
\text { National University (Ivano-Frankivsk, Ukraine) }\end{array}$ \\
\hline & \\
\hline
\end{tabular}

\section{УДК 378.016.018.43.091.279.7: 796-057875 рина Бондаренко, Марина Андрющенко, doi: 10.15330/fcult.35.9-17 Василь Маср, Геннадій Кураса, Олег Бондаренко}

\section{ОЦІНКА ЕФЕКТИВНОСТІ ОРГАНІЗАЦЇ̈ ДИСТАНЦЙНОГО НАВЧАННЯ МАЙБУТНІХ ФАХІВЦІВ 3 ФІЗИЧНОЇ КУЛЬТУРИ}

Мета. Вивчити ефективність організації дистаниійного навчання з використанням платформи Moоdle при підготовці фахівців зі фізичної культури. Методи. В опитуванні взяли участь 365 студентів факультету фізичного виховання та спорту Чернігівського національного університету імені Петра Могили. Використано методи аналізу та узагальнення наукових джерел, нормативних документів, методи математичної статистики. Результати. 3 'ясовано, щзо більшість студентів використовують різні компоненти навчальних курсів. Так, з текстами лекцій дистанційної платформи навчання працює 25\% студентів, робочу навчальну програму аналізує 17\%; екзаменаційні питання та тести - 12,19\%. Студенти (10,6\%) невдоволені змістом та рівнем складності завдань окремих навчальних дисциплін, а також оперативністю викладачів щзодо перевірок виконаних навчальних завдань студентів. Зміст та обсяг навчальних матеріалів, необхідних для вивчення дисииплін 7,2\% студентів вважає незадовільним. 